\title{
Genetic testing for Lynch syndrome in the first year of colorectal cancer: a review of the psychological impact
}

\author{
Karin M. Landsbergen · Judith B. Prins • \\ Han G. Brunner · Floris W. Kraaimaat • \\ Nicoline Hoogerbrugge
}

Published online: 28 March 2009

(C) The Author(s) 2009. This article is published with open access at Springerlink.com

\begin{abstract}
An increasing number of patients with colorectal cancer (CRC) receive genetic counselling within 1 year after diagnosis. Little is known whether specific subgroups are more vulnerable for genetic testing related distress. A literature review was conducted to identify the psychological impact of CRC in the first year, and the additional impact of genetic testing. The electronic databases of PubMed, PsychInfo, Embase and the Cochrane Library were searched to identify all reports published between January 1997 and October 2007 on the psychological impact of (1) CRC-diagnosis up to 1 year after treatment and of (2) genetic testing for Lynch syndrome in patients with CRC. Studies on the psychological impact of genetic testing in newly diagnosed patient with CRC were not available. Either CRC patients diagnosed several years ago were studied and the focus was also often on the psychological impact of genetic testing prior to DNA-test disclosure. They show that limitations in emotional and social functioning can persist up to 1 year after CRC
\end{abstract}

K. M. Landsbergen · H. G. Brunner · N. Hoogerbrugge Department of Human Genetics, Raboud University Nijmegen Medical Centre, Geert Grooteplein zuid 10, 6525 GA Nijmegen, The Netherlands

\section{J. B. Prins · F. W. Kraaimaat}

Department of Medical Psychology, Raboud University

Nijmegen Medical Centre, Geert Grooteplein zuid 10,

6525 GA Nijmegen, The Netherlands

K. M. Landsbergen ( $\bowtie)$

Department of Human Genetics, Radboud University Nijmegen

Medical Centre, P.O. Box 9101, 6500 HB Nijmegen,

The Netherlands

e-mail: k.landsbergen@antrg.umcn.nl treatment, especially in those with a stoma or diagnosed before age 60 . Female patients and male patients diagnosed before age 50 appear to be more vulnerable to genetic testrelated distress. It is well known that being treated for CRC has great impact on psychological functioning. Little is known about the psychological impact during the first year after diagnosis and very little is known about the additional psychological effect of genetic testing for hereditary cancer in this period. We found presumptive evidence that specific subgroups of patients with CRC are more vulnerable for genetic-testing-related distress.

Keywords Colorectal cancer .

Diagnostic genetic testing - Lynch syndrome .

Psychological impact · Review

\section{Introduction}

Up to $5 \%$ of patients with colorectal cancer have Lynch syndrome (hereditary non-polyposis colorectal cancer (HNPCC) [1-3]. Unfortunately, only a small proportion of the expected number of patients undergo genetic testing. Identification of a hereditary predisposition can be lifesaving. When more patients are traced with hereditary colorectal cancer, an increasing number of relatives can receive appropriate surveillance, which will prevent premature death from colorectal cancer [4]. To enhance the detection of Lynch syndrome, a special strategy has been developed for risk patients who cannot be recognized by family history. This new strategy called MIPA involves MSI-testing by pathologist in new patients with CRC below the age of 50 [5]. It is being introduced at an increasing number of hospitals. In this strategy, the pathologists select patients and tumour specimens for 
microsatellite instability (MSI) testing. In case of a positive MSI test, the patient is at risk for Lynch syndrome and thus referred for genetic counseling to a clinical genetic center.

For the patients, the difference between the new strategy and the existing procedure is that genetic counselling and testing is discussed very shortly after the diagnosis of colorectal cancer, instead of a long period after diagnosis and treatment. In this early stage after diagnosis, patients with colorectal cancer may be more emotionally vulnerable. Concurrently, these patients are confronted with three major tasks: (1) to cope with their cancer, (2) to cope with the consequences of a possible genetic risk and (3) to consider informing and discussing genetic counseling and DNA-testing with their blood relatives. Extended work already has been accomplished on familial cancer in general, including colorectal patients tested for Lynch syndrome. In a number of reviews on familial cancer, colorectal cancer was included as one of the familial cancers [6, 7]. Many studies describe the psychological impact of pre symptomatic testing for Lynch syndrome [8-22]. From these studies it can be concluded that in general genetic counselling and pre symptomatic testing for Lynch syndrome can lead to increased distress immediately after DNA-test disclosure but does not lead to long-term adverse effects. Other related studies assessed experiences of patients and family members with genetic counselling for hereditary cancer and [23], the impact of attendance of a familial colorectal clinic on cancer-related concerns [24], subjective perception regarding colorectal cancer [25, 26], compliance with screening after testing [26], genetic testing for Lynch syndrome in colorectal cancer survivors who were more than 1 year after diagnosis [27] and quality of life after various surgical procedures [28].

Obviously, this new Lynch detection strategy gave rise to systematically survey relevant data related to the issue of the impact of symptomatic genetic testing in patients with colorectal cancer in their first year after colorectal cancer diagnosis. A literature review was conducted to identify the psychological impact of colorectal cancer, focusing on the impact of the malignancy during the first year after primary treatment and of the additional impact of genetic testing for Lynch syndrome in affected patients.

\section{Materials and methods}

The electronic databases PubMed and PsychInfo were searched to identify all the reports published between January 1997 and October 2007 on the psychological impact of colorectal cancer and genetic testing for hereditary colorectal cancer (Lynch syndrome) in patients during their first year of colorectal cancer. Two searches were performed in each database.

Search 1 retrieved literature on the psychological impact of the diagnosis and treatment of colorectal cancer. A sensitive search strategy was adopted using the following keywords: colorectal cancer, colorectal tumour(s), colorectal carcinoma, colorectal neoplasms, psychological distress, psychological adaptation, coping, emotional adjustment, anxiety, depression and quality of life. Using these keywords, 470 abstracts were retrieved: 415 from PubMed and 55 from PsychInfo. After removing doubles, one of the reviewers (KL) checked all the titles and abstracts. Full text copies were obtained when the studies had possible relevance. Inclusion criteria were (1) studies on patients in their first year with colorectal cancer (2) psychological outcome measurements, (3) peer-reviewed articles in English, French or Dutch. From studies with a prospective design with long-term follow-up, only the results up to 1 year were retrieved. Exclusion criteria were (1) Patients with colorectal cancer aged $>70$ years. These patients are not generally referred for genetic testing due to their advanced age. (2) Colorectal cancer disease management studies and subjective experiences. (3) Qualitative design. (4) Research into non-standard medical treatment. (5) Publications of which no relevant data (mean scores) could be retrieved. Based on these criteria, 17 studies remained (see Fig. 1).

Search 2 retrieved literature on the psychological impact of genetic testing in patients with colorectal cancer. The keywords in search 1 were used in combination with the terms genetic testing, genetic predisposition to disease, genetic screening, genetic counseling and genetics. Using these keywords, 101 abstracts were retrieved. After removing doubles, one of the reviewers (KL) checked all the titles and abstracts. Full text copies were obtained of all the possibly relevant studies. Inclusion criteria were (1) patients diagnosed with colorectal cancer (2) psychological outcome measurement, (3) peer-reviewed articles in English, French or Dutch. Exclusion criteria were (1) Presymptomatic/predictive testing, because our focus was on the impact of genetic testing in patients diagnosed with colorectal cancer. (2) Qualitative design. (3) Genetic testing for Familial Adenomatous Polyposis (FAP). (4) Publications of which no relevant data (mean scores) could be retrieved. Based on these criteria, ten studies remained (see Fig. 1).

Additional free text searches were performed in PubMed, PsychInfo as well as in the Cochrane Library database and in Embase using all the above-mentioned keywords to select reviews on the psychological impact of colorectal cancer and genetic testing for hereditary colorectal cancer. However, none of these searches led to any relevant publications. 
Fig. 1 Selection of studies on the psychological impact of colorectal cancer until 1 year after treatment $(* 1)$ and diagnostic genetic testing for hereditary colorectal cancer $(* 2)$

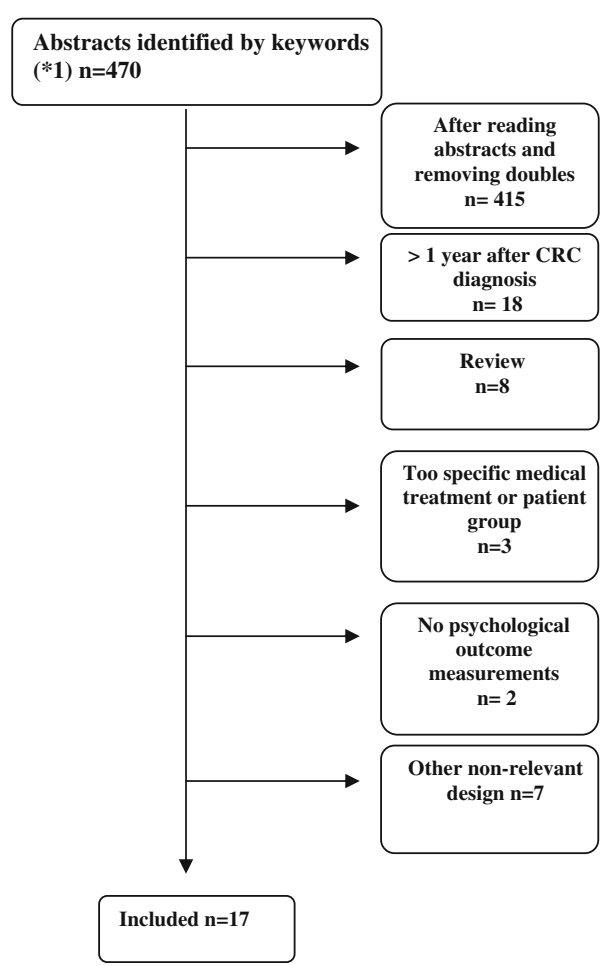

Methodological quality

The studies were assessed according to the guidelines for levels of evidence and grades of recommendation, supplied by the Oxford-Centre for Evidence-based Medicine. A level of evidence (LE) 1 refers to RCT studies, LE2 to cohort studies, LE3 to case-control studies, LE 4 to caseseries and LE5 to expert opinions (http://www.cebm.net/ levels of_evidence.asp).

\section{Results}

I Psychological impact of colorectal cancer

Table 1 gives a summary of each of the 17 papers [29-45] included in our review. The vast majority of the patients with colorectal cancer were older than 50 years. As a result of the heterogeneity of psychological variables and used measurement instruments of the retrieved studies, a limit was set in describing those studies that used the European Organization for Research and Treatment in Cancer (EORTC) QLQ-C30 scale. In ten out of the 17 studies, the European Organization for Research and Treatment in Cancer (EORTC) QLQ-C30 scale had been used to measure the quality of life of the patients [29-32, 35, 41, 43-46]. This scale has frequently been used to assess health-related quality of life in various groups of cancer patients [47].
The mean scores on functional status were retrieved from the studies, because an important aim of this review was to evaluate functioning after treatment for colorectal cancer. The scores are presented in Table 2. Our comparison may not do justice to the special qualities of each individual study, as their designs were intended to provide answers to specific research questions, not to facilitate comparability. Nevertheless the comparison adds new dimensions to our knowledge in this area. To evaluate the significance of these function scores, they were compared to reference data from a random sample $(n=2081)$ of the general (non-cancer) adult population [47] and from breast cancer patients [48] (Table 2). According to the MIPA (MSI test by pathologist) procedure, MSI-positive patients are usually informed about the results and offered genetic testing within 3 months after surgery. Therefore, clear distinction is made between psychological functioning in the first 3 months after treatment and in the subsequent period up to 1 year after treatment. In the publications of Schmidt [42] and Tsunoda [44] the EORTC-QLQ-C30 data were presented in graph and mean data could not be obtained and used reliably. The study of Wilson et al. [45], only presented mean data on EORTC-QLQ-C30 Global Health Status. Therefore, these three studies are not reflected in Table 2 .

Regarding the psychosocial impact of CRC with other instruments than the EORTC-QLQ-C30, it appeared that often different questionnaires were used, concerning patients at different ages, with different types of colorectal 


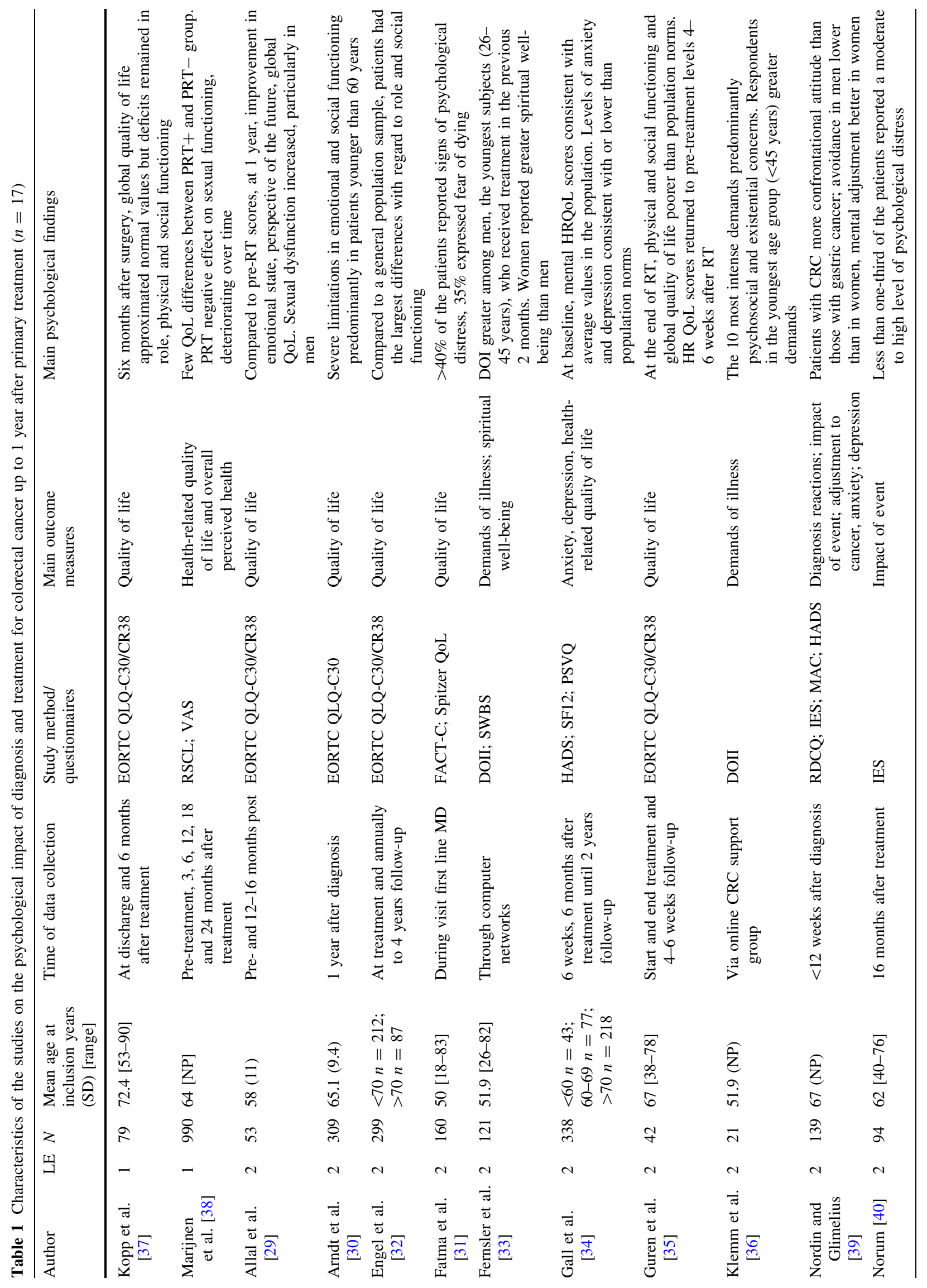




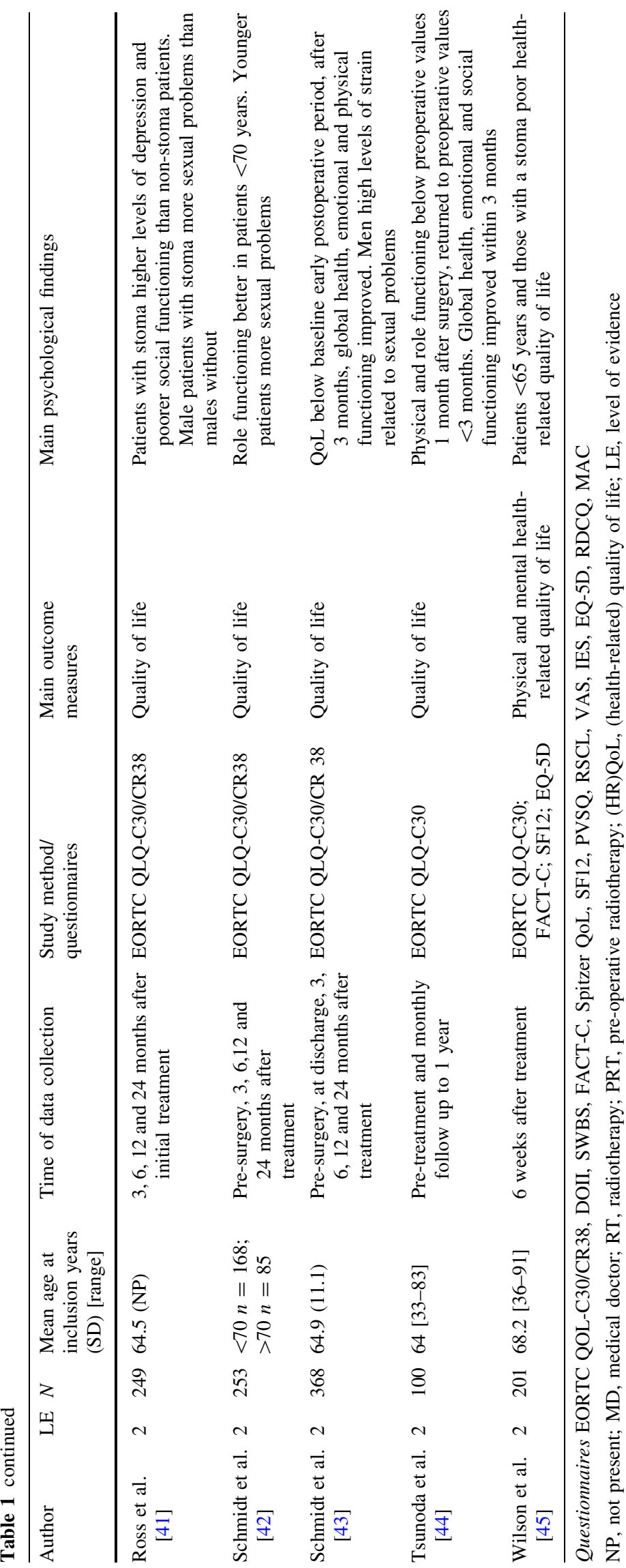




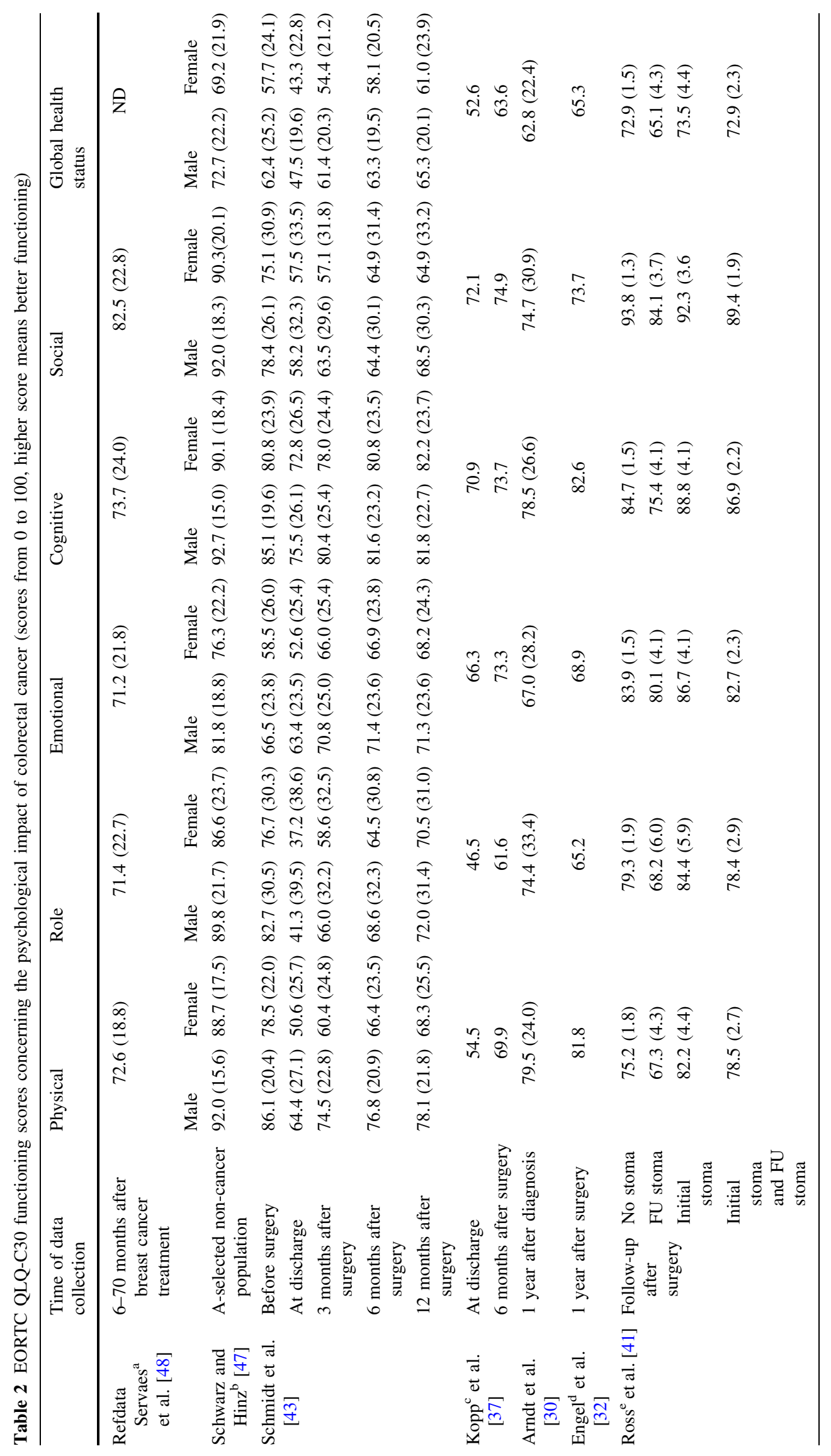




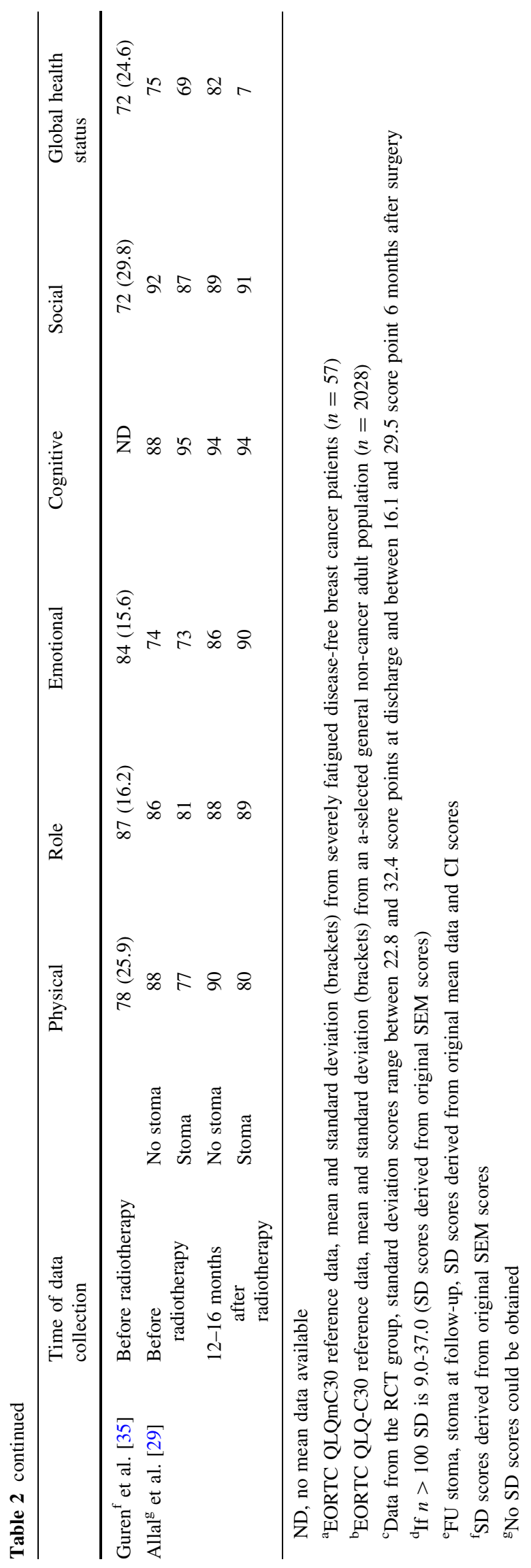

cancer and often with different times of data collection. Still, an overall impression was obtained that demands of illness, especially psychosocial and existential concerns, were greater among the youngest age group below 45 years. Moreover, patients with a stoma showed higher levels of depression and poorer social function than nonstoma patients. Especially men with a stoma reported sexual problems as did patients after treatment for rectal cancer".

Impact of colorectal cancer on functional status

\section{Up to 3 months after treatment}

Table 2 shows that compared to the reference data, colorectal cancer led to reduced social functioning (especially in the patients with a stoma) as well as to decreased role and physical functioning [29, 30, 32, 37, 41, 43]. Patients of younger than 65 years and those with a stoma reported reduced health-related quality of life 6 weeks after surgery [45]. In the group with rectal cancer the men suffered from more problems with their sexual functioning after abdominoperineal resection than the women [43]. It can be concluded that immediately after treatment for colorectal cancer, physical, social and role functioning were diminished especially in patients with a stoma, compared to levels of physical, social and role functioning of a selected sample of adults [47] and of patients with lung cancer (another common malignancy worldwide) [49, 50].

\section{Between 3 and 12 months after treatment}

Reduced role, emotional and social functioning continued up to 1 year after treatment. The women reported poor physical functioning [43] compared to the reference data [47] and the scores from a severely fatigued breast cancer group [48]. Global health status scores of the patients with colorectal cancer were also poorer than the reference data [47]. Severe limitations were found in emotional and social functioning up to 1 year after treatment. These problems were especially likely to affect patients of younger than 60 years [30]. In the men, strain due to sexual impairment appeared to persist $[29,43,46]$; the men with a stoma had more sexual problems than those without [41]. Rectal cancer patients reported poor role and social functioning compared to the reference data [47] up to 1 year after treatment [32]. In the patients who had pre-operative radiotherapy, emotional functioning was impaired compared to the norm data [47]. At 12-16 months after radiotherapy, these scores had returned to normal levels [29]. Thus, severe problems with emotional and social functioning persisted up to 1 year after treatment, 
especially in the patients of younger than 60 years and in those with a stoma.

Impact of colorectal cancer on demands of illness and spiritual well-being

In two studies, patients younger than 45 years reported greater demands of illness (hardships or stressors that require coping or adjustment to illness) than the older patients [33, 36]. Fernsler et al. [33] also showed that such demands of illness were greater in men and in men and women who had received treatment in the previous 2 months; in contrast, the women reported significantly higher spiritual well-being than the men. This leads to the conclusion that colorectal cancer caused more hardships and stressors in men and in patients diagnosed before the age of 45 years.

II Psychological impact of genetic testing for Lynch syndrome

Summaries of the ten relevant studies are shown in Table 3. Nearly all the studies had gathered data on the patients before disclosure of the genetic test result. Two studies had made assessments pre-test and post-test $[16,51]$, whereas one study had only made assessments post-test [52]. Very few studies gave specific details about the time interval since the diagnosis of colorectal cancer and inclusion in the study [53,54]. Table 3 also shows the diversity in outcome measures and (self-administered) questionnaires to gather data $[16,51,55-58]$. The aim of this review was to determine how patients with colorectal cancer reacted to (the offer of) genetic testing. Therefore, the psychological reactions were documented according to stage of genetic testing the patients had reached at the time of the studies. The process of genetic counselling was divided into three distinct stages: (1) Period of genetic counselling and if desired, having a blood sample taken. (2) Period of waiting for the result of the DNA analysis. (3) Period after disclosure of the genetic test result.

\section{Psychological reactions before genetic counselling}

The three relevant studies showed that patients with colorectal cancer tended to have positive attitude towards genetic testing $[56,57,59]$. Their most common motivation to undergo genetic testing was concern about the risk of colorectal cancer in close relatives. Motivation was the highest in the younger patients, in those with early stage disease and in those who had more frequent thoughts about hereditary colorectal cancer [57]. In a group of patients with colorectal cancer who attended an information session about Lynch syndrome, 28\% developed a clinically significant level of cancer-worry-related distress [56]. In conclusion, motivation to undergo genetic testing was primarily the need to know if close relatives were at increased risk for colorectal cancer and was strongly present in younger patients.

Psychological reactions before and after genetic counseling

Other studies obtained data on the patients after patients had consented to have a blood sample taken for DNA analysis. Keller [55] and Murakami found clinically relevant depression scores before and after genetic counseling in 19 and 5\% of the patients, respectively [51]. Another study reported clinically relevant anxiety levels in $32 \%$ of the patients before genetic counseling, whereas the scores dropped to $16 \%$ after genetic counseling [55]. In a group of patients who had given a blood sample for genetic testing, the prevalence of depressive symptoms was $24 \%$, although all the scores remained within the clinically normal range [54]. Patients in the age group of younger than 50 years had higher levels of anxiety and depression but the scores were within the normal range; their data also showed significant associations between pre-test distress, a history of familial mortality from colorectal cancer and anticipation of becoming depressed post-test [53]. Characteristics associated with depression were female sex, less formal education, fewer sources of social contact; associations with anxiety were younger age, less formal education, Non-Caucasian race, more severe disease and fewer sources of social contact [54]. Intrusion scores reached clinically relevant levels in $14 \%$ of the patients [55]. Higher intrusion and avoidance scores were found in women and in the patients who had been diagnosed with colorectal cancer less than 1 year previously, although all the scores remained within the normal clinical range [53]. Clinically relevant cancerworry-related distress was detected in $25 \%$ of the patients before genetic counseling, but after genetic counseling, this dropped to $13 \%$ [55]. In conclusion, most psychological distress scores remained within the normal range before the result of the genetic test was disclosed, although a minority of the patients developed clinically relevant anxiety and depression levels. Vulnerable subgroups were female patients and male patients diagnosed before the age of 50 years.

Psychological reactions after disclosure of the genetic test result

Disclosure of the genetic test result led to significant depression scores in $7 \%$ of the patients and post-traumatic 


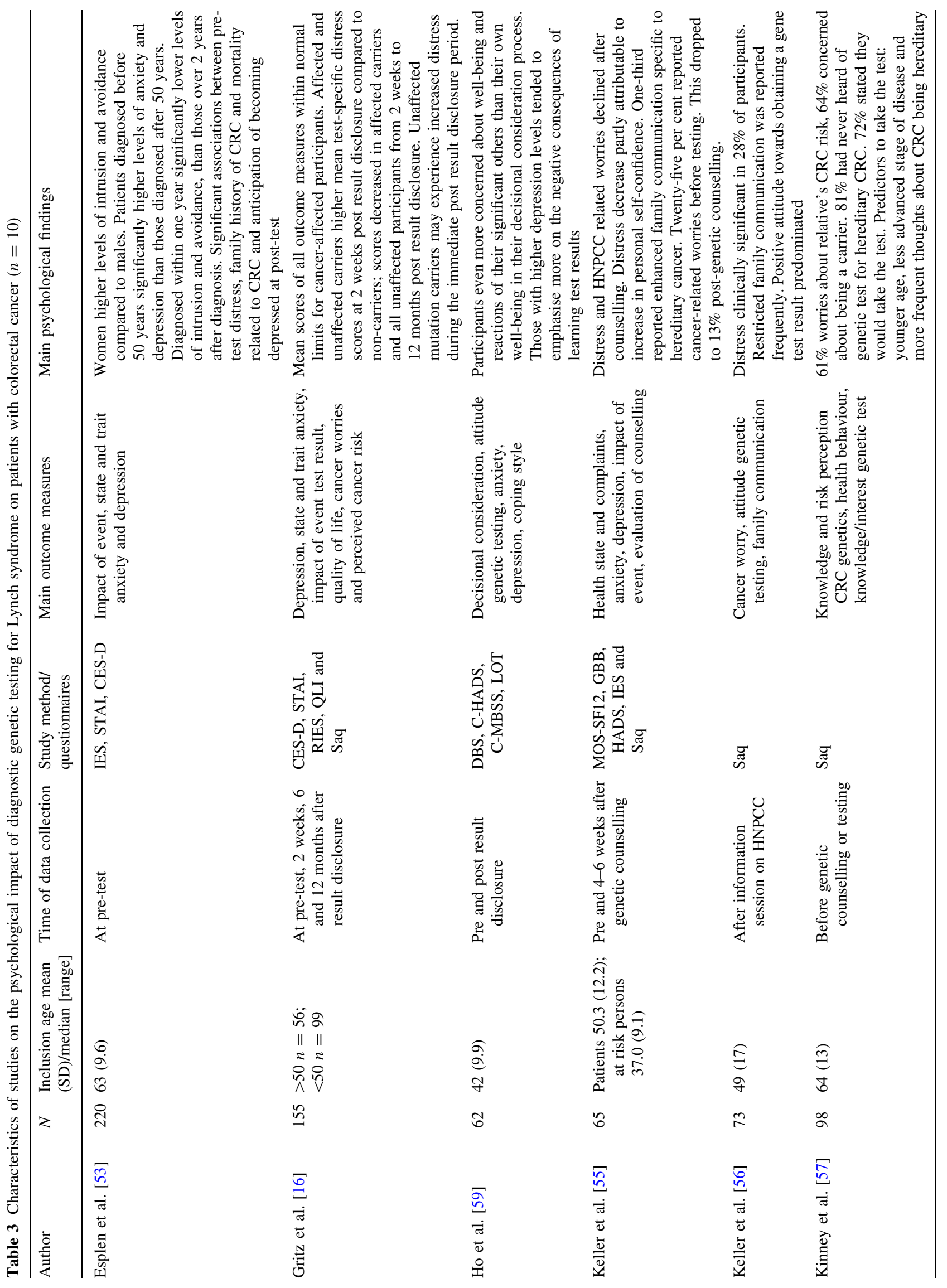




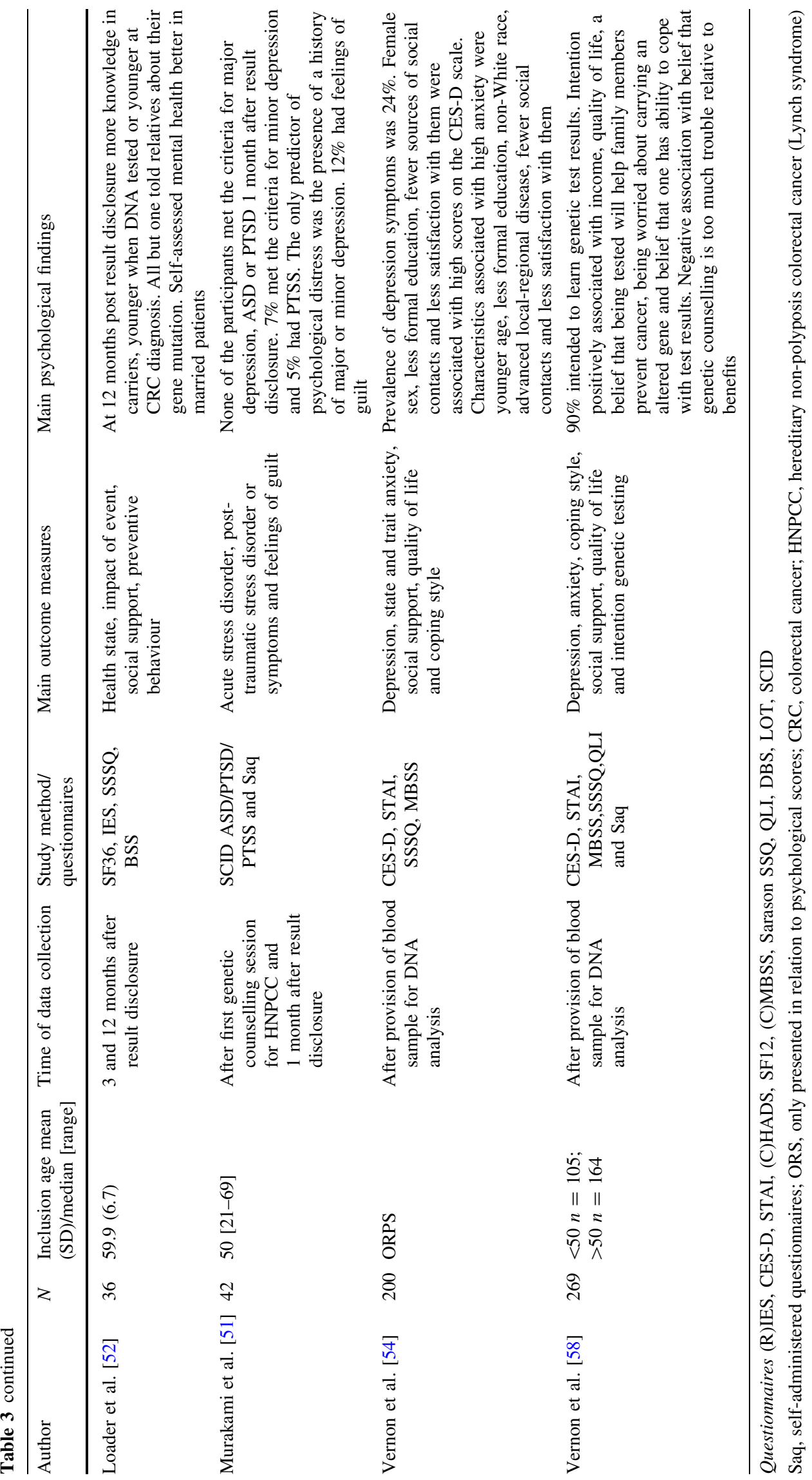


stress symptoms in 5\% [51]. Lynch syndrome mutation carriers showed higher test-specific distress than non-carriers but these scores returned to baseline between 2 and 12 weeks after receiving the test result [16]. The only predictor of psychological distress after disclosure of the test result was a history of depression [51]. It can be concluded that disclosure of the genetic test result did not lead to any relevant levels of psychological distress in most patients. Vulnerable subgroups seemed to be patients with pre-test distress, high familial mortality from colorectal cancer and a history of depression. Therefore, a subgroup of vulnerable patients whose genetic test discloses Lynch syndrome mutation carrier ship may benefit from extra psychological counselling.

\section{Discussion}

This literature review shows that little is known about the additional psychological impact of obtaining a genetic test disclosure in newly diagnosed patients with colorectal cancer. Only ten studies were identified on diagnostic genetic testing in colorectal patients. Most of these studies measured distress prior to genetic test disclosure, but did not obtain data after disclosure of the test result. Prior to disclosure of the genetic test result, female patients and men who were diagnosed with colorectal cancer before the age of 50 years appeared to be more vulnerable to genetictest-related distress. A history of depression and high levels of pre-test distress were strongly associated with genetictest-related distress and cancer related worries. It is generally known that a young age at diagnosis and multiple family members with cancer are hallmarks of heredity. Therefore, significant levels of anticipated psychological distress prior to disclosure of the genetic test result in patients with a history of familial mortality from cancer [53] can also be regarded as relevant to patients with colorectal cancer who are suspected of Lynch syndrome carriership.

The few studies available on distress after disclosure of the genetic test result revealed ambiguous results. For patients with different types of cancer, the impact of genetic testing many years after the initial cancer diagnosis and treatment was strongly influenced by their former experience of cancer [7]. Dorval hypothesized that after disclosure of the genetic test result, cancer patients may be more aware of their own risk developing a second primary tumour and be more conscious of the contribution of genetics to an increased risk of cancer in their offspring [60]. When genetic testing was offered to recently diagnosed colorectal cancer patients, the majority did not object to an active approach [61]. Individuals at high-risk for Lynch syndrome proved to know very little about microsatellite instability (MSI) testing, a hallmark for patients at risk for Lynch syndrome, but held positive attitudes towards MSI test utility [62].

This literature review also shows that most patients with colorectal cancer experience diminished physical, social and role functioning during the first 3 months after primary treatment. Decreased emotional and social functioning could persist for up to 1 year after treatment, especially in patients of younger than 60 years and in those with a stoma. Specific subgroups of patients with colorectal cancer appeared to be more vulnerable to genetic-testingrelated distress, but their actual levels of distress did not generally reach clinical significance. Reduced emotional and social functioning may be related to the many taboos that still surround bowel dysfunction [63]. Especially the younger patients reported severe distress due to maladjustment to their colorectal cancer. Having a stoma can lead to feelings of stigmatisation and lead to withdrawal from social activities $[64,65]$. Recurring themes in patients with colorectal cancer are loneliness and isolation [63]. It might be expected that disabilities after colorectal cancer treatment prevent the younger patients from going to work and contribute to their impaired social and role functioning, but it was found that most patients with colorectal cancer returned to work after treatment [64, 66]. An additional source of distress especially in younger male patients was the possible impact on sexual functioning [64, 67]. Studies have shown that after treatment for rectal cancer, sexual problems were common, inadequately discussed and/or treated by physicians [67]. Furthermore, the potential for impotence due to treatment for colorectal cancer was a serious concern especially in patients of younger than 60 years [64].

\section{Conclusion}

This review identifies the psychological impact of colorectal cancer during the first year after treatment and indicates specific subgroups of patients with colorectal cancer who could be vulnerable for genetic-testing-related distress. Most of the retrieved studies on diagnostic genetic testing for Lynch syndrome exclusively measured distress prior to genetic test disclosure and focused on patients who were diagnosed with colorectal cancer several years ago. Therefore, we are still unable to identify the psychological impact of genetic testing for Lynch syndrome in recently diagnosed patients with colorectal cancer.

Acknowledgments We would like to thank the Netherlands Digestive Diseases Foundation for their financial contribution (SW0507) and Alice Tillema for her support and assistance with the literature search. 
Open Access This article is distributed under the terms of the Creative Commons Attribution Noncommercial License which permits any noncommercial use, distribution, and reproduction in any medium, provided the original author(s) and source are credited.

\section{References}

1. Evans DG, Walsh S, Jeacock J et al (1997) Incidence of hereditary non-polyposis colorectal cancer in a population-based study of 1137 consecutive cases of colorectal cancer. Br J Surg 84:1281-1285. doi:10.1002/bjs.1800840924

2. Ponz de Leon M, Sassatelli R, Benatti P et al (1993) Identification of hereditary nonpolyposis colorectal cancer in the general population. The 6-year experience of a population-based registry. Cancer 71:3493-3501. doi:10.1002/1097-0142(19930601)71:11 $<3493:$ :AID-CNCR2820711106>3.0.CO;2-H

3. Riegler G, Savastano A, Selvaggi F et al (1999) Prevalence of HNPCC in a series of consecutive patients on the first endoscopic diagnosis of colorectal cancer: a multicenter study. The Italian Collaborative Group. Endoscopy 31:337-341. doi:10.1055/ s-1999-30

4. Jarvinen HJ, Aarnio M, Mustonen H et al (2000) Controlled 15year trial on screening for colorectal cancer in families with hereditary nonpolyposis colorectal cancer. Gastroenterology 118:829-834. doi:10.1016/S0016-5085(00)70168-5

5. Kievit W, de Bruin JH, Adang EM et al (2005) Cost effectiveness of a new strategy to identify HNPCC patients. Gut 54:97-102. doi:10.1136/gut.2004.039123

6. Braithwaite D, Emery J, Walter F et al (2004) Psychological impact of genetic counseling for familial cancer: a systematic review and meta-analysis. J Natl Cancer Inst 96:122-133

7. Meiser B (2005) Psychological impact of genetic testing for cancer susceptibility: an update of the literature. Psychooncology 14:1060-1074. doi:10.1002/pon.933

8. Aktan-Collan K, Mecklin JP, Jarvinen H et al (2000) Predictive genetic testing for hereditary non-polyposis colorectal cancer: uptake and long-term satisfaction. Int J Cancer 89:44-50. doi: 10.1002/(SICI)1097-0215(20000120)89:1<44::AID-IJC8>3.0.CO; 2-3

9. Aktan-Collan K, Haukkala A, Mecklin JP et al (2001) Psychological consequences of predictive genetic testing for hereditary non-polyposis colorectal cancer (HNPCC): a prospective followup study. Int J Cancer 93:608-611. doi:10.1002/ijc.1372

10. Aktan-Collan K, Haukkala A, Mecklin JP et al (2001) Comprehension of cancer risk one and 12 months after predictive genetic testing for hereditary non-polyposis colorectal cancer. J Med Genet 38:787-792. doi:10.1136/jmg.38.11.787

11. Carlsson AH, Bjorvatn C, Engebretsen LF et al (2004) Psychosocial factors associated with quality of life among individuals attending genetic counseling for hereditary cancer. J Genet Couns 13:425-445. doi:10.1023/B:JOGC.0000044202.95768.b3

12. Codori AM, Petersen GM, Miglioretti DL et al (1999) Attitudes toward colon cancer gene testing: factors predicting test uptake. Cancer Epidemiol Biomarkers Prev 8:345-351

13. Codori AM, Waldeck T, Petersen GM et al (2005) Genetic counseling outcomes: perceived risk and distress after counseling for hereditary colorectal cancer. J Genet Couns 14:119-132. doi:10.1007/s10897-005-4062-2

14. Fantini C, Pedinielli JL, Manouvrier S (2007) Psychological distress in applicants for genetic screening for colorectal cancer. Encephale 33:117-123. doi:10.1016/S0013-7006(07)91541-9

15. Geirdal AO, Reichelt JG, Dahl AA et al (2005) Psychological distress in women at risk of hereditary breast/ovarian or HNPCC cancers in the absence of demonstrated mutations. Fam Cancer 4:121-126. doi:10.1007/s10689-004-7995-y

16. Gritz ER, Peterson SK, Vernon SW et al (2005) Psychological impact of genetic testing for hereditary nonpolyposis colorectal cancer. J Clin Oncol 23:1902-1910. doi:10.1200/JCO.2005.07.102

17. Hadley DW, Jenkins J, Dimond E et al (2003) Genetic counseling and testing in families with hereditary nonpolyposis colorectal cancer. Arch Intern Med 163:573-582. doi:10.1001/archinte. 163.5.573

18. Meiser B, Collins V, Warren R et al (2004) Psychological impact of genetic testing for hereditary non-polyposis colorectal cancer. Clin Genet 66:502-511. doi:10.1111/j.1399-0004.2004.00339.x

19. Nordin K, Liden A, Hansson M et al (2002) Coping style, psychological distress, risk perception, and satisfaction in subjects attending genetic counselling for hereditary cancer. J Med Genet 39:689-694. doi:10.1136/jmg.39.9.689

20. Claes E, Denayer L, Evers-Kiebooms G et al (2004) Predictive testing for hereditary non-polyposis colorectal cancer: motivation, illness representations and short-term psychological impact. Patient Educ Couns 55:265-274. doi:10.1016/j.pec. 2003.11.002

21. van Oostrom I, Meijers-Heijboer H, Duivenvoorden HJ et al (2007) Comparison of individuals opting for BRCA1/2 or HNPCC genetic susceptibility testing with regard to coping, illness perceptions, illness experiences, family system characteristics and hereditary cancer distress. Patient Educ Couns 65:58-68. doi:10.1016/j.pec. 2006.05.006

22. Collins VR, Meiser B, Ukoumunne OC et al (2007) The impact of predictive genetic testing for hereditary nonpolyposis colorectal cancer: three years after testing. Genet Med 9:290-297. doi:10.1097/GIM.0b013e31804b45db

23. Bleiker EM, Aaronson NK, Menko FH et al (1997) Genetic counseling for hereditary cancer: a pilot study on experiences of patients and family members. Patient Educ Couns 32:107-116. doi:10.1016/S0738-3991(97)00067-0

24. Collins V, Halliday J, Warren R et al (2000) Cancer worries, risk perceptions and associations with interest in DNA testing and clinic satisfaction in a familial colorectal cancer clinic. Clin Genet 58:460-468. doi:10.1034/j.1399-0004.2000.580606.x

25. Claes E, Denayer L, Evers-Kiebooms G et al (2005) Predictive testing for hereditary nonpolyposis colorectal cancer: subjective perception regarding colorectal and endometrial cancer, distress, and health-related behavior at one year post-test. Genet Test 9:54-65. doi:10.1089/gte.2005.9.54

26. Bleiker EM, Menko FH, Taal BG et al (2005) Screening behavior of individuals at high risk for colorectal cancer. Gastroenterology 128:280-287. doi:10.1053/j.gastro.2004.11.002

27. Esplen MJ, Madlensky L, Aronson M et al (2007) Colorectal cancer survivors undergoing genetic testing for hereditary nonpolyposis colorectal cancer: motivational factors and psychosocial functioning. Clin Genet 72:394-401

28. Krouse R, Grant M, Ferrell B et al (2007) Quality of life outcomes in 599 cancer and non-cancer patients with colostomies. J Surg Res 138:79-87. doi:10.1016/j.jss.2006.04.033

29. Allal AS, Gervaz P, Gertsch P et al (2005) Assessment of quality of life in patients with rectal cancer treated by preoperative radiotherapy: a longitudinal prospective study. Int J Radiat Oncol Biol Phys 61:1129-1135. doi:10.1016/j.ijrobp.2004.07.726

30. Arndt V, Merx H, Stegmaier C et al (2004) Quality of life in patients with colorectal cancer 1 year after diagnosis compared with the general population: a population-based study. J Clin Oncol 22:4829-4836. doi:10.1200/JCO.2004.02.018

31. Ben FL, Kallel L, Landolsi A et al (2007) Quality of life in patients with colo-rectal cancers at a Tunisian hospital center. A case control study of a population unhurt by cancer. Tunis Med $85: 380-384$ 
32. Engel J, Kerr J, Schlesinger-Raab A et al (2003) Quality of life in rectal cancer patients: a four-year prospective study. Ann Surg 238:203-213

33. Fernsler JI, Klemm P, Miller MA (1999) Spiritual well-being and demands of illness in people with colorectal cancer. Cancer Nurs 22:134-140. doi:10.1097/00002820-199904000-00005

34. Gall CA, Weller D, Esterman A et al (2007) Patient satisfaction and health-related quality of life after treatment for colon cancer. Dis Colon Rectum 50:801-809. doi:10.1007/s10350-006-0815-8

35. Guren MG, Dueland S, Skovlund E et al (2003) Quality of life during radiotherapy for rectal cancer. Eur J Cancer 39:587-594. doi:10.1016/S0959-8049(02)00741-4

36. Klemm P, Miller MA, Fernsler J (2000) Demands of illness in people treated for colorectal cancer. Oncol Nurs Forum 27:633639

37. Kopp I, Bauhofer A, Koller M (2004) Understanding quality of life in patients with colorectal cancer: comparison of data from a randomised controlled trial, a population based cohort study and the norm reference population. Inflamm Res 53(Suppl 2):S130 S135. doi:10.1007/s00011-004-0361-6

38. Marijnen CA, van de Velde CJ, Putter H et al (2005) Impact of short-term preoperative radiotherapy on health-related quality of life and sexual functioning in primary rectal cancer: report of a multicenter randomized trial. J Clin Oncol 23:1847-1858. doi:10.1200/JCO.2005.05.256

39. Nordin K, Glimelius B (1997) Psychological reactions in newly diagnosed gastrointestinal cancer patients. Acta Oncol 36:803810. doi: $10.3109 / 02841869709001361$

40. Norum J (1997) Adjuvant chemotherapy in Dukes' B and C colorectal cancer has only a minor influence on psychological distress. Support Care Cancer 5:318-321. doi:10.1007/s005200050080

41. Ross L, Abild-Nielsen AG, Thomsen BL et al. (2006) Quality of life of Danish colorectal cancer patients with and without a stoma. Support Care Cancer 15(5):505-513

42. Schmidt CE, Bestmann B, Kuchler T et al (2005) Ten-year historic cohort of quality of life and sexuality in patients with rectal cancer. Dis Colon Rectum 48:483-492. doi:10.1007/s10350-0040822-6

43. Schmidt CE, Bestmann B, Kuchler T et al (2005) Gender differences in quality of life of patients with rectal cancer. A fiveyear prospective study. World J Surg 29:1630-1641. doi:10.1007/ s00268-005-0067-0

44. Tsunoda A, Nakao K, Hiratsuka K et al (2007) Prospective analysis of quality of life in the first year after colorectal cancer surgery. Acta Oncol 46:77-82. doi:10.1080/02841860600847053

45. Wilson TR, Alexander DJ, Kind P (2006) Measurement of healthrelated quality of life in the early follow-up of colon and rectal cancer. Dis Colon Rectum 49:1692-1702. doi:10.1007/s10350006-0709-9

46. Schmidt CE, Bestmann B, Kuchler T et al (2005) Impact of age on quality of life in patients with rectal cancer. World J Surg 29:190-197. doi:10.1007/s00268-004-7556-4

47. Schwarz R, Hinz A (2001) Reference data for the quality of life questionnaire EORTC QLQ-C30 in the general German population. Eur J Cancer 37:1345-1351. doi:10.1016/S0959-8049(00) 00447-0

48. Servaes P, Verhagen S, Bleijenberg G (2002) Determinants of chronic fatigue in disease-free breast cancer patients: a cross-sectional study. Ann Oncol 13:589-598. doi:10.1093/annonc/mdf082

49. Montazeri A, Milroy R, Hole D et al (2003) How quality of life data contribute to our understanding of cancer patients' experiences? A study of patients with lung cancer. Qual Life Res 12:157-166. doi:10.1023/A:1022232624891

50. Montazeri A, Hole DJ, Milroy R et al (2004) Does knowledge of cancer diagnosis affect quality of life? A methodological challenge. BMC Cancer 4:21. doi:10.1186/1471-2407-4-21
51. Murakami Y, Okamura H, Sugano K et al (2004) Psychologic distress after disclosure of genetic test results regarding hereditary nonpolyposis colorectal carcinoma. Cancer 101:395-403. doi:10.1002/cncr.20363

52. Loader S, Shields C, Rowley PT (2005) Impact of genetic counseling and DNA testing on individuals with colorectal cancer with a positive family history: a population-based study. Genet Test 9:313-319. doi:10.1089/gte.2005.9.313

53. Esplen MJ, Urquhart C, Butler K et al (2003) The experience of loss and anticipation of distress in colorectal cancer patients undergoing genetic testing. J Psychosom Res 55:427-435. doi:10.1016/S0022-3999(03)00511-7

54. Vernon SW, Gritz ER, Peterson SK et al (1997) Correlates of psychologic distress in colorectal cancer patients undergoing genetic testing for hereditary colon cancer. Health Psychol 16:73-86. doi:10.1037/0278-6133.16.1.73

55. Keller M, Jost R, Haunstetter CM et al (2002) Comprehensive genetic counseling for families at risk for HNPCC: impact on distress and perceptions. Genet Test 6:291-302. doi:10.1089/ 10906570260471822

56. Keller M, Jost R, Kadmon M et al (2004) Acceptance of and attitude toward genetic testing for hereditary nonpolyposis colorectal cancer: a comparison of participants and nonparticipants in genetic counseling. Dis Colon Rectum 47:153-162. doi:10.1007/ s10350-003-0034-5

57. Kinney AY, Choi YA, DeVellis B et al (2000) Attitudes toward genetic testing in patients with colorectal cancer. Cancer Pract 8:178-186. doi:10.1046/j.1523-5394.2000.84008.x

58. Vernon SW, Gritz ER, Peterson SK et al (1999) Intention to learn results of genetic testing for hereditary colon cancer. Cancer Epidemiol Biomarkers Prev 8:353-360

59. Ho SM, Ho JW, Chan CL et al (2003) Decisional consideration of hereditary colon cancer genetic test results among Hong Kong Chinese adults. Cancer Epidemiol Biomarkers Prev 12:426-432

60. Dorval M, Patenaude AF, Schneider KA et al (2000) Anticipated versus actual emotional reactions to disclosure of results of genetic tests for cancer susceptibility: findings from p53 and BRCA1 testing programs. J Clin Oncol 18:2135-2142

61. Porteous M, Dunckley M, Appleton S et al (2003) Is it acceptable to approach colorectal cancer patients at diagnosis to discuss genetic testing? A pilot study. Br J Cancer 89:1400-1402. doi:10.1038/sj.bjc.6601332

62. Manne SL, Chung DC, Weinberg DS et al (2007) Knowledge and attitudes about microsatellite instability testing among high-risk individuals diagnosed with colorectal cancer. Cancer Epidemiol Biomarkers Prev 16:2110-2117. doi:10.1158/1055-9965.EPI-070412

63. Taylor C (2001) Patients' experiences of 'feeling on their own' following a diagnosis of colorectal cancer: a phenomenological approach. Int J Nurs Stud 38:651-661. doi:10.1016/S00207489(00)00109-7

64. Dunn J, Lynch B, Rinaldis M et al (2006) Dimensions of quality of life and psychosocial variables most salient to colorectal cancer patients. Psychooncology 15:20-30. doi:10.1002/pon.919

65. MacDonald LD (1984) Stigma in patients with rectal cancer: a community study. J Epidemiol Community Health 38:284-290. doi:10.1136/jech.38.4.284

66. Sanchez KM, Richardson JL, Mason HR (2004) The return to work experiences of colorectal cancer survivors. AAOHN J 52:500-510

67. Hendren SK, O'Connor BI, Liu M et al (2005) Prevalence of male and female sexual dysfunction is high following surgery for rectal cancer. Ann Surg 242:212-223. doi:10.1097/01.sla.0000 171299.43954.ce 